\title{
Parasitic Myomas Due to Laparoscopic Intra-abdominal Morcellation
}

\author{
Giulia Giovanardi, MD, Stephane Oden, MD, Haitham Khalil, MD, Loic Marpeau, MD, PhD, \\ Renato Seracchioli, MD, Horace Roman, MD, PhD \\ Minimally Invasive Gynaecological Surgery Unit, S. Orsola-Malpighi Hospital, University of Bologna, Bologna, Italy \\ (Drs. Giovanardi, Seracchioli).
}

Department of Gynecology and Obstetrics, Roven University Hospital, Roven, France

(Drs. Oden, Khalil, Marpeau, Roman).

\begin{abstract}
Introduction: The use of electric tissue morcellators is crucial to allow the extraction of voluminous parts from a small laparoscopic incision, especially when the vagina is not opened. This report discusses how morcellation could be associated with the risk of intra-abdominal parasitic myomas developing.

Cases Description: Three women were affected by intra-abdominal parasitic myomas several years after laparoscopic hysterectomy or myomectomy with specimen extraction by morcellation. The myomas were discovered either by accident (case 3) or because the patients were symptomatic (cases 1 and 2). The symptoms are usually unspecific.

Discussion: The use of a morcellator may be associated with the risk of disseminated myoma fragments during the procedure and the rare development of complications from parasitic myomas. Meticulously inspecting the abdominal cavity at the end of the procedure and assessing the size of the uterus and fibroids before the procedure can reduce this risk. It is very likely that these cases are underestimated because patients may be asymptomatic and these parasitic myomas can occur years after the operation.
\end{abstract}

Key Words: Myoma, Parasitic myoma, Morcellation, Myomectomy, Laparoscopic hysterectomy.

Citation Giovanardi G, Oden S, Khalil H, Marpeau L, Seracchioli R, Roman H. Parasitic myomas due to laparoscopic intra-abdominal morcellation. CRSLS e2013.00239. DOI: $10.4293 /$ CRSLS.2013.00239

Copyright $(2015$ by SLS, Society of Laparoendoscopic Surgeons. This is an open-access article distributed under the terms of the Creative Commons Attribution-Noncommercial-ShareAlike 3.0 Unported license, which permits unrestricted noncommercial use, distribution, and reproduction in any medium, provided the original author and source are credited.

Address correspondence to: Horace Roman, MD, PhD, Clinique Gynécologique et Obstétricale, Centre Hospitalier Universitaire "Charles Nicolle," 76031 Rouen, France. Telephone: +332 328889 90/61 509; Fax: +33 235981 149, E-mail: horace.roman@gmail.com

\section{INTRODUCTION}

Myomas, also known as fibroleiomyomas, are benign tumors of the uterus that consist of muscular and fibrous components. They are the most common solid tumors, with single or multiple presentations in $20 \%$ to $25 \%$ of patients of reproductive age and in 30\% to $40 \%$ of women aged older than 40 years. ${ }^{1,2}$ These tumors develop in the smooth muscle elements of the uterus and are monoclonal. Their etiology is still unclear; however, an association with estrogen level has been established.

Case reports over the past 10 years have described masses that were myometrial in nature according to histopathol- ogy and had spread into the abdominal cavity. The most common site of parasitic myomas was the pelvis, including the paravesical, pararectal, and rectovaginal spaces. ${ }^{3}$ However, cases have also been described in the upperright quadrant, the anterior abdominal wall, and previous port locations. ${ }^{3}$

Different theories have been put forward to explain these findings. The first theory is that pedunculated subserosal myomas have torsion of the pedicle and require nourishment from other vessel sources, such as the omental and mesenteric vessels. ${ }^{4} \mathrm{~A}$ second theory is that these lesions develop in the metaplasia of the peritoneum, in primitive multipotent mesenchymal subcoelomic stem cells, under 


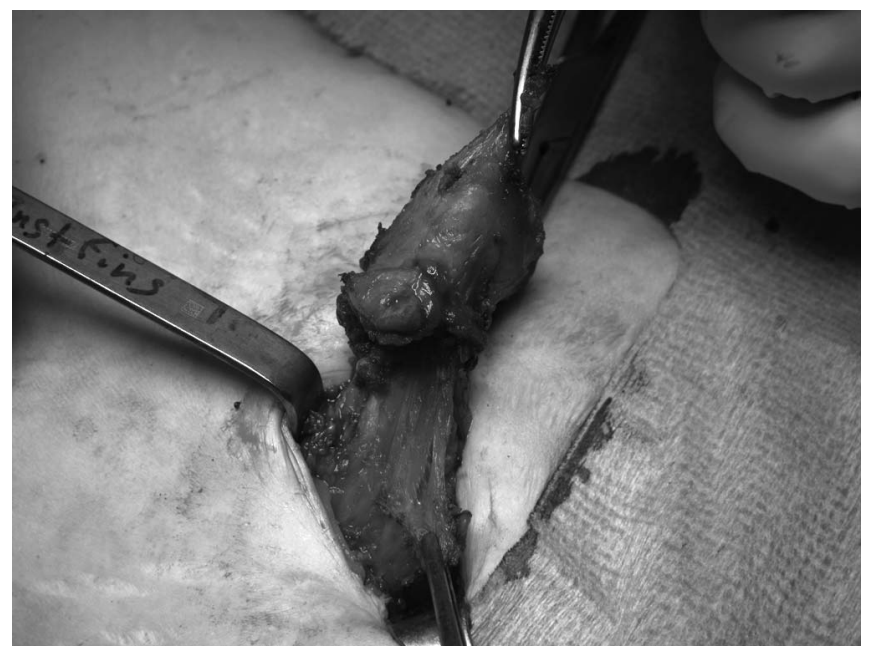

Figure 1. Surgical removal of parasitic myoma in right abdominal muscles in case 1 , showing stages of enucleation.

the effect of sex hormones. ${ }^{4}$ A hypothesis has recently emerged that these myomas are iatrogenic in origin, particularly after laparoscopic surgery and the use of a morcellator. ${ }^{5}$ Since the 1990s, the laparoscopic approach has become increasingly popular. Total hysterectomies, subtotal hysterectomies, and myomectomies are performed daily in many hospitals. ${ }^{2,3}$ The use of a morcellator is crucial to allow the extraction of voluminous parts from a small laparoscopic incision, especially when the vagina is not opened. ${ }^{2,3,5}$ Several case reports in the literature have described rare cases of parasitic myomas due to the increased use of laparoscopy and electric tissue morcellators. ${ }^{1-12}$

The rate of parasitic myomas after laparoscopic morcellation seems to range from $0.1 \%$ to $1.2 \%, 2,5$ and the mean rate of parasitic myomas due to supracervical hysterectomy is $0.57 \% .^{3}$ However, these rates have likely been underestimated because patients may be asymptomatic and these myomas can occur years after the operation. ${ }^{5}$

A recent review identified 13 case reports that have been published in the literature: 9 reports on single cases, 2 reports on 2 cases each, 1 report on 4 cases, and 1 report on a series of 10 cases. Nine of 13 studies have been published since $2005 .{ }^{5}$

The 3 cases in this report were treated at Rouen University Hospital, and this report will focus on the particular circumstances that favor the occurrence of parasitic myomas.

\section{METHODS}

This study was a retrospective observational analysis of 3 patients who underwent laparoscopic hysterectomy or
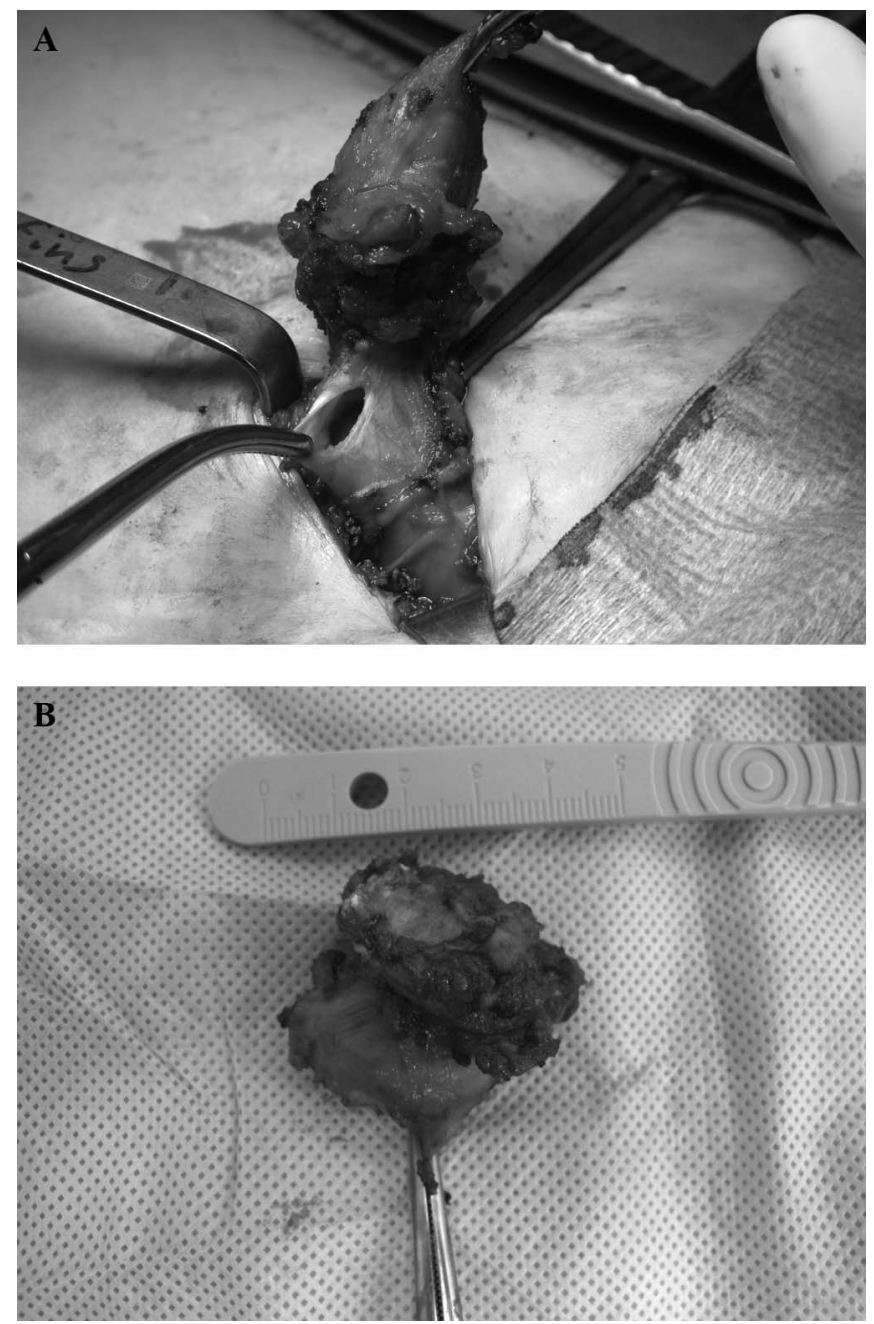

Figure 2. Surgical removal of parasitic myoma in right abdominal muscles in case 1: stages of enucleation (A) and enucleated myoma (B).

myomectomy with specimen extraction by morcellation and in whom secondary intra-abdominal parasitic myomas developed. Laparoscopic surgical procedures were performed in our department; therefore, the complete medical records and intraoperative information were available for review.

\section{Case 1}

A 39-year-old woman, para 3, without major antecedents and with contraceptive pill intake, had complained of pelvic discomfort with heaviness and deep dyspareunia for 2 years. A clinical examination showed an enlarged uterus, and mobilization was painful. Pelvic ultrasonography showed an adenomyotic uterus with multiple subse- 


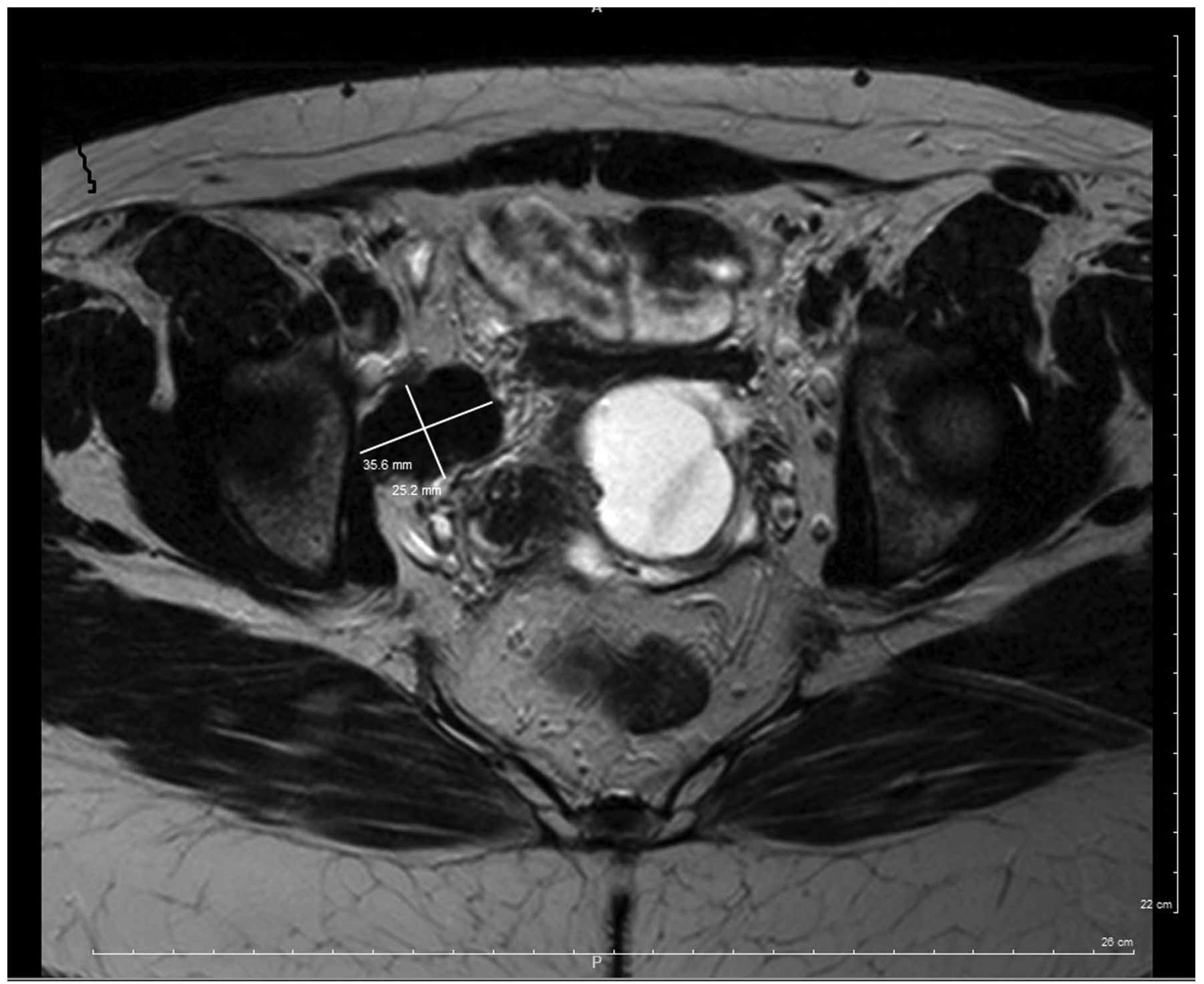

Figure 3. MRI examination in case 2, showing peritoneal leiomyomatosis.

rous and interstitial fibroids with diameters that ranged from 1 to $3 \mathrm{~cm}$. The patient underwent laparoscopic hysterectomy with intra-abdominal uterine morcellation. The histologic examination of the extracted slices showed a leiomyoma with muscle tissue and hyaline collagen, which weighed approximately $250 \mathrm{~g}$. No cellular atypical features, necrosis, or abnormal mitosis was found. The immediate outcomes were favorable. Five months later, the patient was referred for a $3-\mathrm{cm}$ hard tumor in the right abdominal muscles that was $5 \mathrm{~mm}$ below the orifice of the median subumbilical trocar scar where the morcellator had been inserted. The nodule was spontaneously sensitive and limited the physical activity of the patient. Four- teen months after the hysterectomy, a general surgeon removed the nodule whose limits were well defined by a cleavage plane (Figures 1 and 2). The anatomic and pathologic examinations indicated an adenomyotic nodule with no malignancy features.

\section{Case 2}

A 39-year-old woman, para 1, was referred for menometrorrhagia. She had been followed up for stage C3 human immunodeficiency virus and arterial hypertension. A physical examination showed an enlarged uterus with a superior limit that was $5 \mathrm{~cm}$ above the navel. The mag- 
Parasitic Myomas Due to Laparoscopic Intra-abdominal Morcellation, Giovanardi G et al.
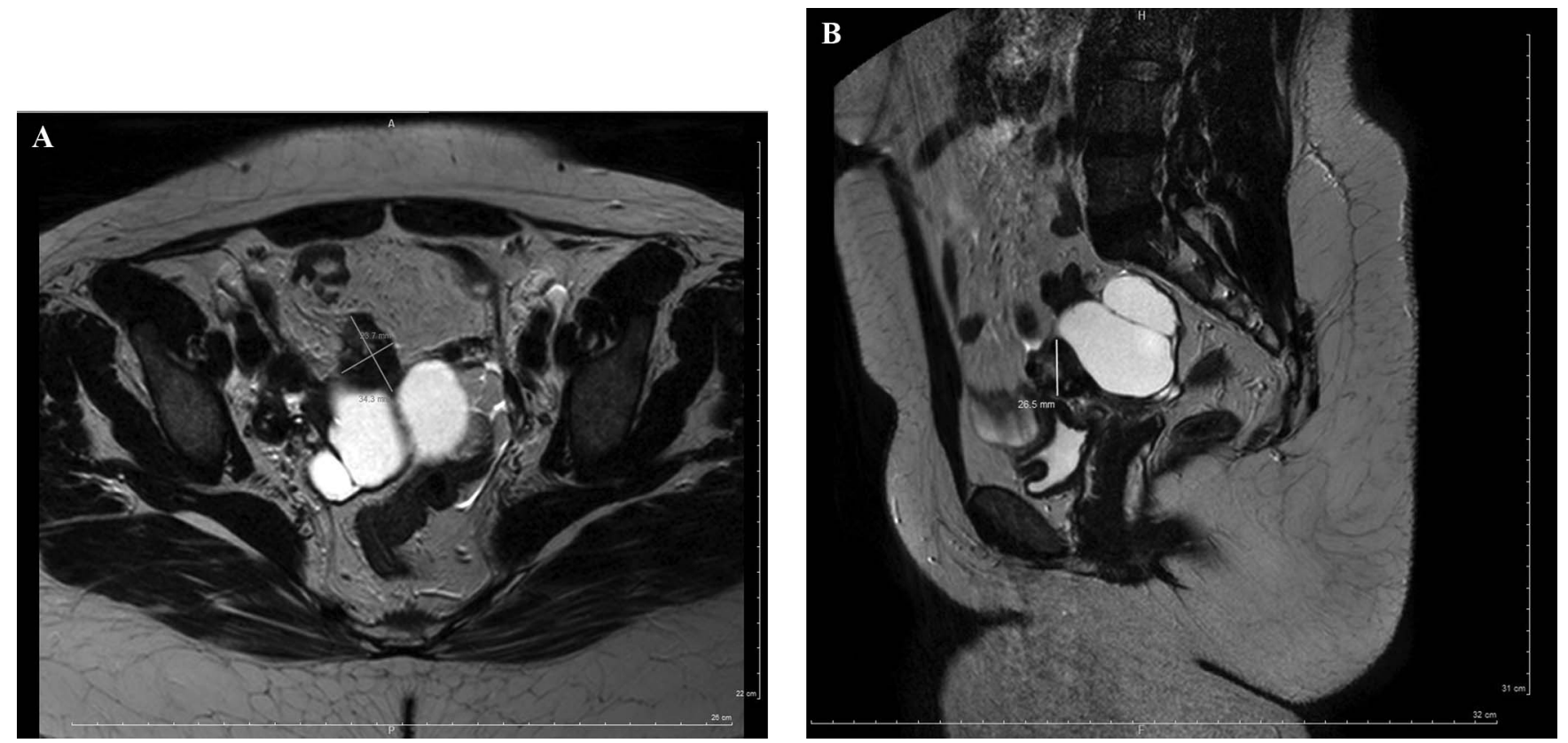

Figure 4. (A, B) MRI examination in case 2, showing peritoneal leiomyomatosis.

netic resonance imaging (MRI) examination showed a bulky and fibromatous uterus with a paramedian isthmic myoma that measured $12 \times 9 \times 9 \mathrm{~cm}$, a paramedian myoma that measured $6 \times 5 \mathrm{~cm}$, and an intracavitary myoma that was $17 \mathrm{~mm}$ in diameter. The surgery was delayed for 1 year according to the wishes of the patient, and triptorelin was administered for 1 year with percutaneous estradiol as add-back therapy. Then, a total laparoscopic hysterectomy was performed with the primary ligation of the uterine arteries at their origins. ${ }^{6}$ After complete primary uterine devascularization, a 1600-g uterus was removed with a $12-\mathrm{mm}$ mechanical morcellator. The mean duration of the morcellation stage was 2 hours 50 minutes. Despite the inherent difficulties because of the large size of the uterus, we did not observe any intraoperative or postoperative complications. The histologic analysis of the uterus components suggested leiomyoma fibromatosis with thickened endometrium, quiescent fibrous tissue, smooth muscle, and hyaline collagen.

Five years after the surgical procedure, the patient complained of dysuria, deep dyspareunia, and spontaneous pain located in the right iliac fossa and in the back. The MRI examination showed a bilateral hydrosalpinx that was $35 \mathrm{~mm}$ on each side, a right ovarian liquid cyst, and several tumors with well-defined polylobed borders in a markedly low T2 sequence and a high T1 sequence. These lesions were located on the right obturator muscle $(52 \times$ $25 \times 36 \mathrm{~mm})$, the right round ligament $(32 \times 16 \times 35$ $\mathrm{mm})$, the bladder $(34 \times 24 \times 26 \mathrm{~mm})$, the right ovary $(26 \times 21 \times 35 \mathrm{~mm})$, and the left internal iliac vessels $(17 \times$ $10 \times 21 \mathrm{~mm}$ ) (Figures 3 and 4). The diagnosis of peritoneal leiomyomatosis was most likely. The patient has not agreed to undergo surgical management and received only intermittent analgesic therapy.

\section{Case 3}

A 36-year-old woman, followed up for Steinert syndrome, who was childless despite 2 previous in vitro fertilization procedures, was initially referred to our emergency department for amenorrhea of 5 weeks' duration, followed by metrorrhagia. The $\beta$ human chorionic gonadotropin ( $\beta$ hCG) hormone level was $700 \mathrm{IU} / \mathrm{mL}$. The ultrasonographic examination did not show an intrauterine pregnancy but did show a parauterine mass that measured $70 \times 70 \times 46 \mathrm{~mm}$ with features that suggested a subserous myoma. The patient underwent biopsy curettage; however, the results did not show an intrauterine pregnancy. Therefore, laparoscopy was performed and found no ectopic pregnancy; only a subserous myoma was found, and it was removed by hysterotomy, enucleation, and morcellation. The diagnosis of spontaneous abortion was affirmed.

Three years later, the patient presented with a new spontaneous pregnancy. A systematic ultrasonographic examination was performed at 4 weeks' gestation. Surprisingly, the examination showed a living embryo that was $18 \mathrm{~mm}$ 


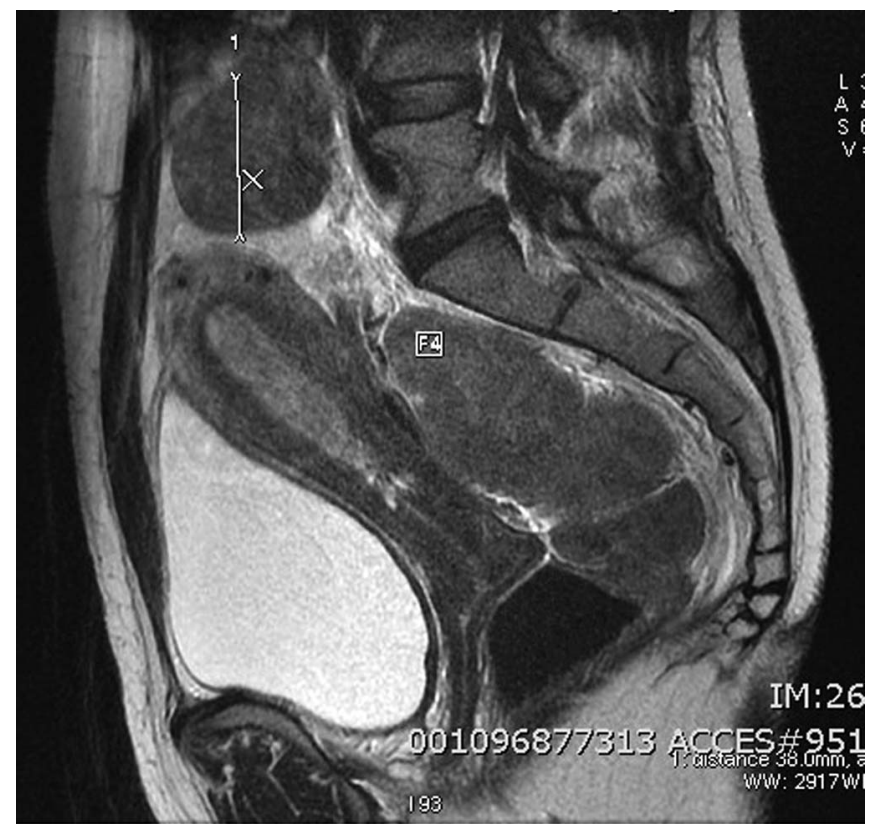

Figure 5. MRI examination in case 3, showing multiple large intraperitoneal myomas.

in length and was located in the left uterine cornu. The $\beta$-hCG hormone level was $125 \mathrm{IU} / \mathrm{mL}$.

Laparoscopy was performed in the emergency department and confirmed a cornual ectopic pregnancy, which was treated by the in situ administration of $50 \mathrm{mg}$ of methotrexate. In addition, the surgeon observed multiple large intraperitoneal myomas, which were postoperatively evaluated by an MRI examination (Figures $\mathbf{5}$ and 6). The myomas were located in the pelvis and the abdomen, and their diameters ranged from 24 to 110 $\mathrm{mm}$. The patient benefited from close follow-up, and the $\beta$-hCG hormone level progressively decreased within 5 weeks down to undetectable values. Despite the lack of specific symptoms related to the myomas, their rapid growth during a 3-year period required their surgical removal through open surgery to provide specimens for histologic analysis. The definitive diagnosis was multiple benign myomas.

\section{DISCUSSION}

The actual prevalence of parasitic myomas has not been assessed even though several reports have recently been published in the literature. It is likely that numerous patients with parasitic myomas either are overlooked because they are managed elsewhere or go undiagnosed because the symptoms are attributed to other etiologies,
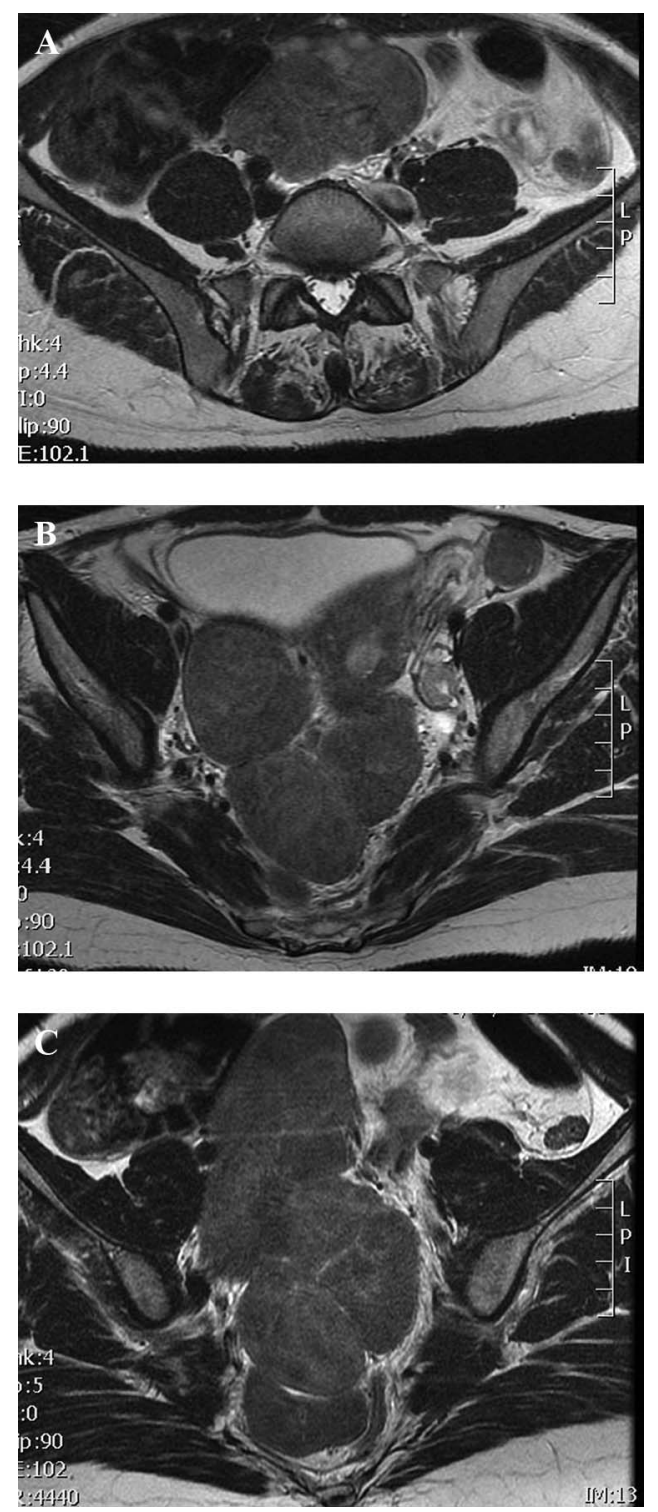

Figure 6. (A-C) MRI examination in case 3, showing multiple large intraperitoneal myomas.

such as postoperative adhesions or gastrointestinal diseases.

Parasitic myomas may detach from the uterus and implant spontaneously in the peritoneum or may be the residue of previous morcellation. Several case reports have suggested that morcellation is an iatrogenic condition for the development of newly disseminated peritoneal lesions.7,8 It is likely that several fragments of myometrial tissue will be left in the abdomen during the first surgical procedures. 9 Parasitic myomas are usually found in the pelvis because leiomyoma cells could behave the same as en- 
dometrial cells that implant during endometriosis.5,10 In our series all of the women had previously been managed by laparoscopy with uterine or fibroma morcellation; therefore, they are likely to be concerned about the risks associated with this technique.

In addition, it is possible that other factors contribute to the occurrence of parasitic myomas, such as various growth factors, steroid hormones, and the predisposition of the individual. $2,3,5$ The spread of tissue fragments may be extremely common during laparoscopic morcellation; however, the development of complications, such as a secondary myoma, is rare. 5 The development of parasitic myomas is similar to endometrial implants, which require rapid neovascularization to grow. ${ }^{3}$

Parasitic myomas may be shown either by chance (case 3 ) or because patients are symptomatic (cases 1 and 2). The symptoms are usually unspecific and include pelvic pain, abdominal distention, dyspareunia, and pelvic heaviness.

When patients are referred with unusual abdominal or pelvic tumors, key information for a diagnosis includes previous laparoscopic morcellation. ${ }^{1}$ Then, when abdominal and pelvic MRI shows intraperitoneal tumors with an appearance that is similar to that of the myometrium, parasitic myomas may be considered.

It is likely that the occurrence of parasitic myomas can be prevented by detecting and removing any small fraction of morcellated tissue. This process can be easy and quick when the uterus is small; however, the process may be challenging in patients with large and soft myomas, obese patients, and patients with enlarged uteri that require a long duration of morcellation. In addition to careful inspection of the abdominal cavity at the end of surgery, the surgeon may reveal small uterine fragments by placing the patient in the reverse Trendelenburg position and copiously irrigating the abdomen and pelvis. ${ }^{1,8}$

In addition, in rare patients who present with unexpected intrauterine foci of a leiomyosarcoma, the intra-abdominal spreading of uterine fragments may lead to disease dissemination and severely impair the prognosis of the patients. ${ }^{11,12}$ Several authors have recommended rigorously ruling out the risk of malignancy before surgery3; however, this objective may not be met in all cases, regardless of the imaging technique that is used.

Laparoscopic hysterectomy of a large uterus shows surgical craft because avoiding a laparotomy benefits the health of the patient. However, case 2 provides evidence of delayed complications because of the inability of surgeons to remove hundreds of small pieces of tissue that had spread during a long morcellation procedure. In our opinion, after having performed numerous laparoscopic hysterectomies in huge uteri, we believe that an appropriate uterus size needs to be determined for laparoscopy because this approach may be more harmful than useful to patients. The size limit for uteri may be $1000 \mathrm{~g}$ unless a new minimally invasive technique can be used to minimize the risk of leaving disseminated fragments in the abdomen and to reduce the duration of morcellation.

\section{CONCLUSION}

The use of morcellation may be associated with the risk of disseminated myoma fragments during the procedure and the development of complications from parasitic myomas. The lack of meticulous inspection of the abdominal cavity at the end of the procedure and the laparoscopic management of enlarged uteri and fibroids can be related to the risk of parasitic myomas.

\section{References:}

1. Sinha R, Lakhotia S, Kadam P, Rao G, Mahajan C. Parasitic myoma after morcellation. J Gynecol Endosc Surg. 2009;1(2): 113-115.

2. Leren V, Langebrekke A, Qvigstad E. Parasitic leiomyomas after laparoscopic surgery with morcellation. Acta Obstet Gynecol Scand. 2012;91(10):1233-1236.

3. Larraín D, Rabischong B, Khoo CK, Botchorishvili R, Canis M, Mage G. "Iatrogenic" parasitic myomas: unusual late complication of laparoscopic morcellation procedures. J Minim Invasive Gynecol. 2010;17(6):719-724.

4. Vaquero ME, Magrina JF, Leslie KO. Uterine smooth-muscle tumors with unusual growth patterns. JMinim Invasive Gynecol. 2009; 16(3):263-268.

5. Cucinella G, Granese R, Calagna G, Somigliana E, Perino A. Parasitic myomas after laparoscopic surgery: an emerging complication in the use of morcellator? Description of four cases. Fertil Steril. 2011;96(2):e90-e96.

6. Roman H, Zanati J, Friederich L, Resch B, Lena E, Marpeau L. Laparoscopic hysterectomy of large uteri with uterine artery coagulation at its origin. JSLS. 2008;12(1):25-29.

7. Paul PG, Koshy AK. Multiple peritoneal parasitic myomas after laparoscopic myomectomy and morcellation. Fertil Steril. 2006;85(2):492-493.

8. LaCoursiere DY, Kennedy J, Hoffman CP. Retained fragments after total laparoscopic hysterectomy. J Minim Invasive Gynecol. 2005;12(1):67-69. 
9. Kumar S, Sharma JB, Verma D, Gupta P, Roy KK, Malhotra N. Disseminated peritoneal leiomyomatosis: an unusual complication of laparoscopic myomectomy. Arch Gynecol Obstet. 2008; 278(1):93-95.

10. Vercellini P, Abbiati A, Viganò P, et al. Asymmetry in distribution of diaphragmatic endometriotic lesions: evidence in favour of the menstrual reflux theory. Hum Reprod. 2007;22(9): $2359-2367$.
11. Leung F, Terzibachian JJ, Gay C, et al. Hysterectomies performed for presumed leiomyomas: should the fear of leiomyosarcoma make us apprehend non laparotomic surgical routes?. Gynecol Obstet Fertil. 2009;37(2):109-114.

12. Seidman MA, Oduyebo T, Muto MG, Crum CP, Nucci MR, Quade BJ. Peritoneal dissemination complicating morcellation of uterine mesenchymal neoplasms. PLoS One. 2012; 7(11):e50058 